\title{
Vegetation Produce an Extensive Cooling Effect
}

\author{
Alamah Misni \\ Faculty of Architecture, Planning and Surveying, \\ Universiti Teknologi MARA, Shah Alam, Malaysia \\ alamahmisni@gmail.com
}

\begin{abstract}
This Every garden design is different and has its identity and style, dictated by site, size, microclimate and the preferences of their creators. The recorded data and analysis conducted for this research included the general landscape design, garden size, and data about the five main categories of soft landscaping, includes trees, shrubs, vines, groundcover and turf. In tropical regions, trees are the most important plant structure in a garden. Foliage-canopy structures and vertical woody species distribution are important factors, as they can influence shading, evapotranspiration and the channeling of the wind.

Keywords: Single-family house, thermal performance, landscape design, evapotranspiration

eISSN 2398-4279 @ 2018. The Authors. Published for AMER ABRA cE-Bs by e-International Publishing House, Ltd., UK. This is an open access article under the CC BY-NC-ND license (http://creativecommons.org/licenses/by$n c-n d / 4.0 /$ ). Peer-review under responsibility of AMER (Association of Malaysian Environment-Behaviour Researchers), ABRA (Association of Behavioural Researchers on Asians) and cE-Bs (Centre for EnvironmentBehaviour Studies), Faculty of Architecture, Planning \& Surveying, Universiti Teknologi MARA, Malaysia.
\end{abstract}

DOI: https://doi.org/10.21834/ajqol.v3i10.114 


\subsection{Introduction}

Vegetation is the general term for the plant life of a region. The vegetation structure relates to the number of vertical height layers of plants. In tropical regions, trees are the most important plant structure in a garden. The use of trees, shrubs and groundcovers in the production of shade, evapotranspiration, and channeling the wind depends on their size, species and location. The shrubs, vines, and groundcover situated on the east and west sides can provide shade from the direct sunlight on walls and glass windows. Turf adequately covered all earth surfaces completely around the garden to help evapotranspiration cooling. Evapotranspiration cooling from greater numbers of trees, shrubs and other small sized soft landscape elements around the house would also help to provide a cool, comfortable, and pleasant environment in the surrounding garden.

\subsection{Literature Review}

The tropical and subtropical zones contain the greatest variety of plants in the world, with an estimated minimum of 200,000 species (Sparrow \& Hanly, 2002). According to Casper (2007), besides having several canopies, the favorable conditions of the tropics encourages diverse plant life, which include trees, palms, shrubs, climbers, grasses, groundcover, and lawn. In tropical regions, trees are the most important plant structure in a garden. They often grow, particularly fast and can be the most satisfying plants in the garden (Sparrow \& Hanly, 2002). Large trees with spreading branches help to keep the houses cool. Foliage-canopy structures and vertical woody species distribution are also important factors, as they can influence shading, evapotranspiration and the channeling of wind.

The "cool effect" is defined as a change in the climatological micro conditions in a vegetated (green) area (Saaroni, Bitan, Dor, \& Feller, 2004). The change is manifested at lower temperatures and higher relative humidity $($ Oke, 1988). Oke states that green areas are more humid and, therefore, cooler than their surroundings due to evapotranspiration processes. The shade of vegetation also prevents direct radiation from reaching the ground surface and warming it, thereby resulting in lower air temperatures above these surfaces. The air near the ground in green areas is cooler as a result of the evapotranspiration process. According to Santamouris (2001) and Misni \& Allan (2010), evapotranspiration contributes to creating lower temperature spaces in the urban environment. The evaporation cools the leaves and the surrounding air in contact with them, and at the same time increases the humidity of the air (Givoni, 1991).

Numerous studies simulating the effect of vegetation on urban temperatures have been performed by various researchers. The computer simulation by Huang et al. (1987) predicted that increasing tree cover by $25 \%$ in Sacramento and Phoenix, USA, would decrease air temperature at 2.00 p.m. in July of 3.3 to $5.6^{\circ} \mathrm{C}$. Taha (1997) reported that the factors that affect temperature reduction are evaporative cooling and shading. He concluded that vegetation cover of $30 \%$ could produce a noontime cool of up to $6^{\circ} \mathrm{C}$ cooler in favorable conditions and night time heat island of $2^{\circ} \mathrm{C}$. Evapotranspiration and shading play a role in creating the cooling effect (Saaroni et al., 2004). According to Bernatzky (1982) and Misni (2013), they reduce the local temperature by $2-4^{\circ} \mathrm{C}$. In hot-humid tropical climates, 
landscape design plays a significant role in determining the extent of the cool effects on a neighborhood scale.

\subsection{Methodology}

\section{House study}

Data collection was carried out on 50 single-family houses in Putrajaya and Shah Alam, Malaysia. House study involved the construction and surrounding landscape of aged 5-30 years old. While their construction was similar, the design and size of each house varied because they were built in different eras of construction methods, and styles of architecture and landscaping. The different ages of construction were chosen because they provided different landscaping styles, which would have different effects on the thermal performance of the houses.

\section{Landscape element measurements}

The study of all landscape elements was conducted through observation and interviews with the owner of each house. Landscape elements and house plans were drawn in detail and to scale. The location of every type of vegetation was recorded at $5 \mathrm{~m}$ intervals extending out from the building from each of four azimuths. Tree azimuth classes were defined regarding building wall orientation. Every type of plants was coded with several names and sizes.

\section{Data analysis}

Once all of the data were collected, master spreadsheets were developed using Origin 8.0. All vegetation data gathered from the four azimuths of each house and was recorded numerically in this spreadsheet as percentages or figures. This data was analyzed based on a few variables, including vegetation structure and typology. The actual amount of every type of vegetation could appear as an average or mean to represent the surrounding landscape for every sample house.

\subsection{Findings and Discussions}

\section{Trees}

There are approximately 102 species of tropical trees around the study areas. Palm categories were the most popular, representing approximately $38 \%$ of all trees, followed by garden trees $(25 \%)$ and edible fruit trees $(18 \%)$. Roadside trees were located on access roads and represented around $13 \%$ of trees in the study area. There were also some roadside palms $(5 \%)$ and bamboos (1\%) but less of these were planted by around $5 \%$ and $1 \%$ of the total respectively. The total number of trees in the study area was 542 . The average number of trees for houses was 11 per house. This consisted of two roadside trees or palms, three garden trees, four garden palms, and two edible fruit trees. 


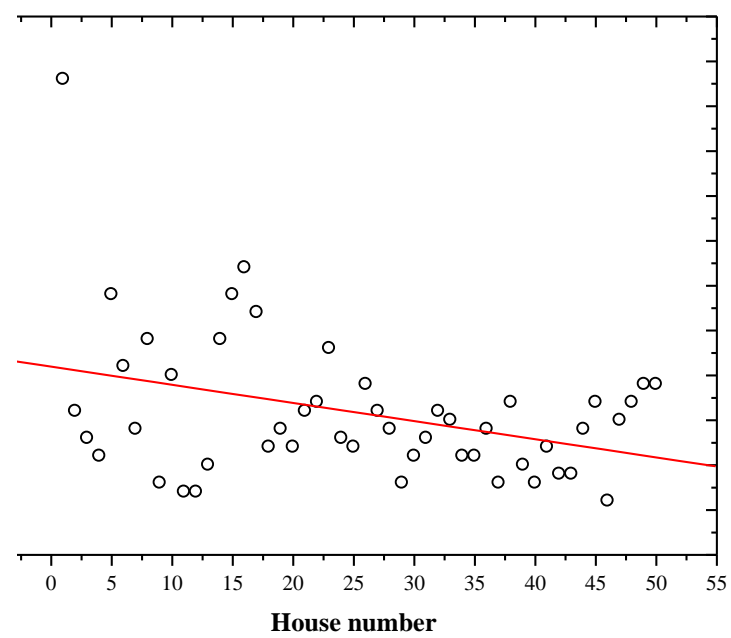

$\circ$ Tree distribution - Linear data (tree distribution)

Figure 1. The distribution of trees around the houses

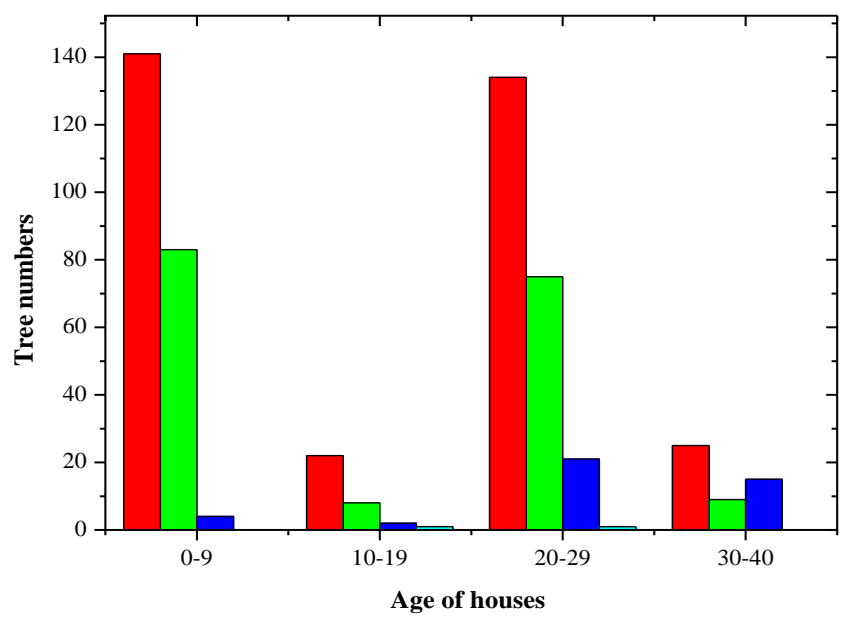

Small $\square$ Small moderate $\square$ Medium $\square$ Large

Figure 2. Tree sizes for the different age groupings of the houses 
The canopy sizes of the trees in the study area were divided into four groups, where the measurements were of the diameter: small $(2-4 \mathrm{~m}$ diameter, $1-2 \mathrm{~m}$ trunk height and $2-4 \mathrm{~m}$ overall height), small-moderate (4-7m diameter, $2-3 \mathrm{~m}$ trunk height and $5-9 \mathrm{~m}$ overall height), medium ( $8-11 \mathrm{~m}$ diameter, $2.5 \mathrm{~m}$ and above, and $10-14 \mathrm{~m}$ overall height), and large (12-15m diameter, $3 \mathrm{~m}$ and above trunk height, and $15-19 \mathrm{~m}$ overall height). The majority of trees in the study areas were small, some because this was how they grew, and for others it was because the trees were still young. There were 322 small-sized trees, which represented $59 \%$ of the total number of trees located around the houses; 176 trees were small-moderate sized (33\%); 42 were medium-sized (8\%); and only 2 were large $(0.4 \%)$. The small sized trees were dominant in almost all of the age groupings of houses, followed by small-moderate size. There were two major sizes and amounts of leaves: small and medium.

The majority was situated on the east (18\%), and west (15\%) sides. The north and south sides had $13 \%$ and $14 \%$ of trees respectively, while the northeast, southeast, southwest, and northwest areas had between 9 and $12 \%$. The distance between the trees and buildings was divided into four categories, which ranged between $0-20 \mathrm{~m}$. The majority of trees were situated between 6 and $10 \mathrm{~m}$ from the houses (51\%), followed by $44 \%$ that were between 0 and $5 \mathrm{~m}, 3.5 \%$ were within $11-15 \mathrm{~m}$ and $1.5 \%$ between 16 and $20 \mathrm{~m}$.

\section{Shrubs, vines, groundcover and turf}

Most of the tropical shrubs in the study areas were flowering or edible plants, palms, and bamboo. Shrubs were dominant on the site, with 1715 species while there were 65 species of vines and 44 groundcover species.

Table 1. Categories of shrubs, vines and groundcover

\begin{tabular}{llll}
\hline $\begin{array}{l}\text { Plant } \\
\text { category }\end{array}$ & Group of plant & $\begin{array}{l}\text { Plant } \\
\text { numbers }\end{array}$ & Total items \\
\hline Shrubs & Garden shrubs & 1247 & \\
& Edible shrubs & 289 & \\
& Palms & 164 & \\
Vines & Bamboo & 15 & 1715 \\
& Garden vines & 48 & \\
Groundcover & Edible vines & 17 & 65 \\
\hline Total & Groundcover & 44 & 44 \\
\hline
\end{tabular}

There are 316 different species of shrubs, vines, and groundcover that was found in the gardens. Figure 3 shows the distribution of shrubs, vines and groundcover around the houses. The linear data show that the average number of shrubs, vines, and groundcover ranged between 18 and 53 species per house, with an average of 36 . This included an average of 34 individual and groups of shrubs and 1 planting of vines and 1 group of groundcover. 
The shrubs, vines and groundcover were divided into five sizes, including individual plants and groups. The majority of shrubs, vines, and groundcover in the study areas were planted individually, but close to other species. $58 \%$ or 1054 of the shrubs, vines and groundcover in the gardens were planted individually, while $29 \%$ were in Group 1 (which included plants sized between 0 and $\left.10 m^{2}\right)$, Group $2\left(11-20 m^{2}\right) 9 \%$, Group $3\left(21-30 m^{2}\right) 4 \%$ and Group $4\left(31-40 \mathrm{~m}^{2}\right) 1 \%$. The average size and amount of leaves was medium.

The distribution of shrubs, vines and groundcover was spread around all areas around the houses. The majority was situated on the east and west sides, representing around $16 \%$ on each side. The north and south areas had 13\% each while northeast, southeast, southwest, and northwest had $9 \%$ and $11 \%$. The percentage of shrubs, vines, and groundcover at the four age groups of the house was similar for each. The distances between the shrubs, vines and groundcover and the buildings have been divided into five categories. The majority of shrubs, vines and groundcover were between $2-5 \mathrm{~m}$ from the buildings $(68.5 \%), 17.3 \%$ were close to walls, $10.5 \%$ were between $5-10 \mathrm{~m}$ and plants between $11-$ $15 \mathrm{~m}$ and $16-20 \mathrm{~m}$ each formed less than $0.3 \%$ of the total. The average shrub height of the houses in the study area was between 0.7 and $1.15 \mathrm{~m}$. The linear data shows that the average height was in the range 0.77 to $0.85 \mathrm{~m}$.

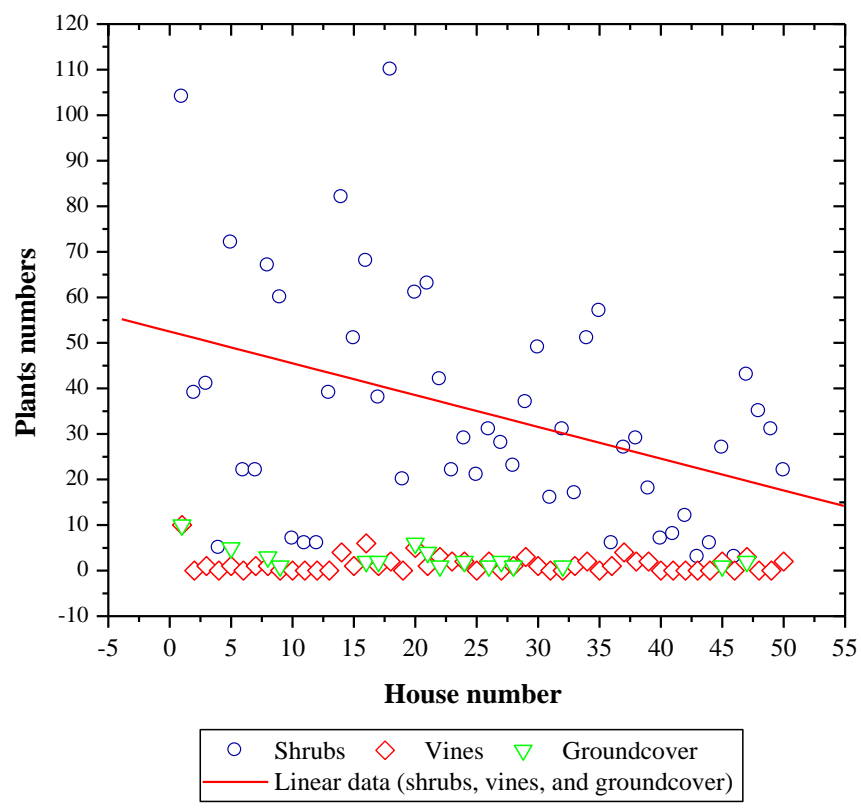

Figure 3. Shrubs, vines and groundcover distribution around the houses in the study areas

Two species of turf were planted in the study areas: $88 \%$ of the houses had Axonopus compressus while the remaining $12 \%$ had planted Cynadon dactylon. $75 \%$ of the garden 
surfaces were covered with turf while the remaining surfaces were covered with other plants.

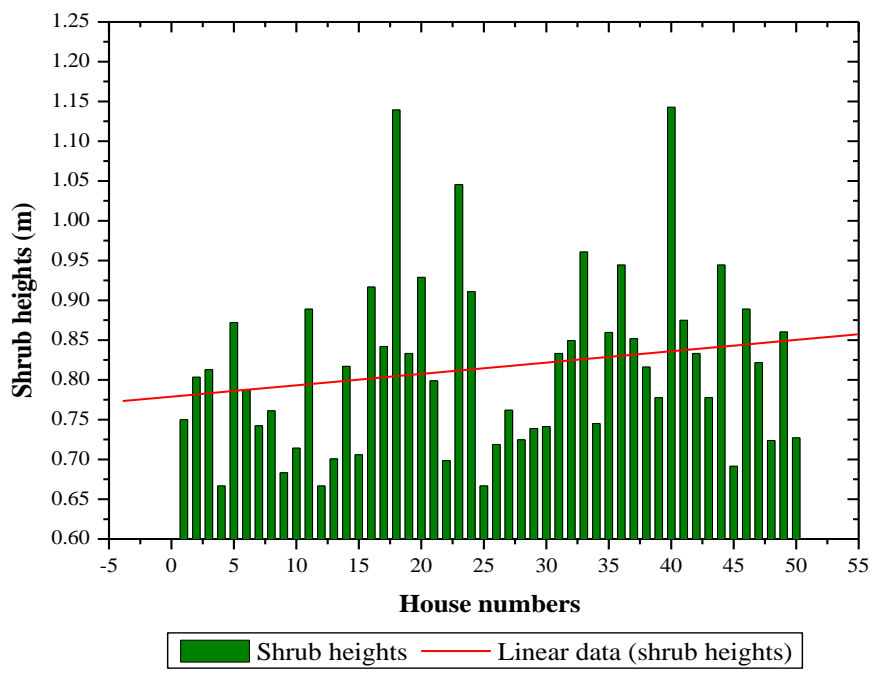

Figure 4. Average shrub heights at each house

\section{Strategically designed of landscaping produce extensive cooling effect}

Trees were the most important components in moderating ground temperature, to produce evapotranspiration cooling and to provide shade in and under their foliage. Their primary function was to provide shade to buildings and the surrounding gardens, which helped reduce heat gain to the buildings, especially during the peak time of the day. Tree average distributions are 11 trees per house. Small sized trees were dominant in almost $60 \%$, followed by small-moderate sized trees, which accounted for around 33\% of the trees. Trunk heights also were suitable for promoting the wind flow to the surrounding garden and building surfaces. Even though the size of trees was only small to small-moderate, the number of trees in each garden, combined with other soft landscape elements such as shrubs, vines, groundcover and turf, were sufficient to produce shade, channel wind and produce evapotranspiration cooling as suggested by McPherson, Herrington and Heisler (1988).

In all of the gardens in the study areas, the trees were scattered around the houses. The majority was situated in the east (18\%) and west (15\%) sides of the houses. These areas are the most critical directions around houses and gardens for landscaping, as they receive direct solar radiation. Having the majority of trees in these areas is an example of strategic landscaping, as they provide shade and help minimize direct solar radiation from entering buildings and the surrounding gardens. It is also important to shade other areas of the house and garden due to diffused solar radiation. On average, the north sides of the houses had $13 \%$ of the trees and the south side $14 \%$.

The majority of trees (51\%) are located in 6 and $10 \mathrm{~m}$ and $44 \%$ between $3-5 \mathrm{~m}$ were close 
enough to the houses to provide shade efficiently while trees that were between 6 and $10 \mathrm{~m}$ from houses could only provide shade to some part of the walls. However, the smallmoderate and medium sized trees, which were as much as $9 m-14 m$ high, were able to provide shade to part of the roof. All trees between 3 and $5 \mathrm{~m}$ and 6 and $10 \mathrm{~m}$ provided extensive shade to the ground surfaces close to the houses, while the remaining $5 \%$ of the trees, which were between 11 and $20 \mathrm{~m}$ from the houses, provided shade to the surrounding garden. As a result, all trees regardless of their distance from the houses assisted in keeping the ambient temperature cool and comfortable.

In the study areas, shrubs were the dominant types of vegetation, with 1,715 species, while the vines were made up of 65 species, and groundcover 44 species. The average was 36 species per house. Most of the shrubs, vines, and groundcover in the study areas were planted in groups and close to other plants, helps to provide more shade to the surrounding gardens and houses. Similar to the trees, the majority was situated in the east and west areas, with approximately $16 \%$ of all shrubs, vines, and groundcover in each area. The majority of the plants in these areas were in strategic locations to provide shade and minimize the effects of direct solar radiation to houses and their surrounding gardens. The north and south sides, where indirect or diffuse solar radiation affects houses, each had around $13 \%$ of shrubs, vines, and groundcover.

There was no minimum distance for shrubs, vines and groundcover from the houses, as their shallow and small root systems cannot harm the floor or foundation structures, and their branches could not hurt the wall surfaces. Almost $70 \%$ of shrubs, vines, and groundcover in the study areas were located $2-5 \mathrm{~m}$ from the houses while $17 \%$ were close to the walls. The average height of the shrubs was between 0.7 and $1.15 \mathrm{~m}$, which was sufficient to provide shade to walls and windows. Between 0 and $5 \mathrm{~m}$ shrubs distance was close enough to the houses adequately to shade the garden surfaces and the walls during the morning and late afternoon when the sun is low in the sky. The shrubs, vines and groundcover between 0 and $20 \mathrm{~m}$ from the houses provided extensive shade to the ground garden surfaces close to the houses and gardens. This helped to keep the ambient temperature near the houses cool and comfortable. The function of turf surfaces was to cover soil surfaces with cool greenery. Even though turf is small and short, it shades the ground and keeps it cool, as well as reducing glare from reflected solar radiation to the building envelopes. $75 \%$ of all the garden surfaces covered by turf also play a role in evapotranspiration cooling of the garden.

\section{Conclusion}

The typical tropical landscape design has been widely practiced in the study areas. Sufficient amounts and sizes of native tropical evergreen plant species were used to produce lively and harmonious garden designs, which provided a pleasant and comfortable ambient air around the garden. Due to their size, trees were the most effective at providing usable shade for the houses and garden surfaces, while shrubs, vines, groundcover, and turf also provided shade on a small-scale. They all channeled the wind flow towards the houses and produced evapotranspiration cooling for the houses and surrounding gardens. Most of them are located on the east and west sides of the houses, where they received direct solar radiation. 
Sufficient numbers and sizes of trees, which were supported by shrubs, vines and groundcover located in strategic positions, can increase the cooling potential of a house, particularly during the peak time of the day. These plants will help to cool the ambient air temperatures, and furthermore can help decrease cooling energy use.

\section{References}

Bernatzky, A. (1982). The contribution of tress and green spaces to a town climate. Energy and Buildings, 5(1), 110.

Casper, J. K. (2007). Plants: Life from the Earth. New York Infobase Publishing

Givoni, B. (1991). Impact of planted areas on urban environmental quality: A review. Atmospheric Environment Part B Urban Atmosphere, 25(3), 289-299.

Huang, Y. J., Akbari, H., Taha, H., \& Rosenfeld, A. H. (1987). The potential of vegetation in reducing summer cooling loads in residential building. Climate and Applied Meteorology, 26, 1103-1116.

McPherson, E. G., Herrington, L. P., \& Heisler, G. M. (1988). Impacts of vegetation on residential heating and cooling Energy and Buildings, 12, 41-51.

Misni, A. (2013). Modifying the Outdoor Temperature around Single-Family Residences: The Influence of Landscaping. Procedia - Social and Behavioral Sciences, 105(0), 664-673.

Misni, A., \& Allan, P. (2010). Sustainable Residential Building Issues in Urban Heat Islands - The Potential of Albedo and Vegetation Paper presented at the Sustainable Building Conference (SB10) New Zealand Wellington. http://www.cmsl.co.nz/assets/sm/5928/61/2.PN003Misni.pdf

Oke, T. R. (1988). Boundary Layer Climates. London Routledge Taylor \& Francis Group

Saaroni, H., Bitan, A., Dor, E. B., \& Feller, N. (2004). The mixed results concerning the 'oasis effect' in a rural settlement in the Negev Desert, Israel. Journal of Arid Environments, 58(2), 235-248.

Santamouris, M. (2001). The role of green spaces. In M. Santamouris (Ed.), Energy and Climate in the Urban Built Environment (pp. 145-159). London James \& James (Science Publishers) Ltd.

Simpson, J. R. (2002). Improved estimates of tree-shade effects on residential energy use. Energy and Buildings, 34(10), 1067-1076.

Sparrow, J., \& Hanly, G. (2002). Subtropical Plants for New Zealand Gardens. Auckland Random House New Zealand

Taha, H. (1997). Urban climates and heat islands: albedo, evapotranspiration and anthropogenic heat. Energy and Building, 25, 99-103. 